\title{
Antitrust enforcement in dynamic network industries
}

\author{
BY DANIEL L. RUBINFELD*
}

\section{Introduction}

The ongoing legal confrontation between the Antitrust Division of the Department of Justice and Microsoft has generated substantial commentary about competition and innovation in the computer software industry. During the fall of 1987 the debate centered on Microsoft's requirement that original equipment manufacturers "bundle" the Microsoft Internet Explorer browser with Microsoft's Windows 95 operating system. The range of issues grew somewhat during the spring of 1998 as concerns became focused on allegations relating to the tying of Internet Explorer to Windows $98 .{ }^{1}$ While it would be dangerous to forecast the likely

* Deputy Assistant Attorney General, Antitrust Division, U.S. Dept. of Justice.

AUTHOR'S NOTE: I wish to thank Wayne Dunham, Joseph Farrell, Ken Heyer, and Carl Shapiro for their helpful comments on an earlier draft.

1 On May 19, 1998 the Department of Justice, 20 state attorneys general, and the District of Columbia filed suit in federal court charging Microsoft with engaging in anticompetitive and exclusionary practices

(c) 1998 by Federal Legal Publications, Inc. 
implication of the browser cases or for that matter the future dynamic of the software industry, it appears likely that the debate surrounding the Internet Explorer browser and the Windows operating system will have broader implications for the application of the antitrust laws to rapidly evolving high-technology companies generally.

In dynamic high-technology industries the antitrust enforcement stakes are raised. On one hand, because the path of innovation today will significantly affect future product quality and price, the potential benefits of enforcement are huge. On the other hand, because the path of innovation is highly uncertain and technology is rapidly changing, the potential costs of enforcement errors are also large. These higher stakes make it essential that sound antitrust enforcement principles be developed and appropriately applied. I believe it vital that while being appropriately cautious about criticizing aggressive procompetitive behavior, the antitrust authorities make every effort to insure that dominant incumbent firms with monopoly power (firms with the ability to raise prices above and/or reduce quality below competitive levels and/or to exclude competitors) not use their substantial market power to harm innovation, to retard technological progress, and ultimately to harm consumers. ${ }^{2}$

I begin with an overview of some of the important economic principles that often apply to the evaluation of the unilateral behavior of firms in network industries. Following each discussion of economic principles, I suggest some antitrust enforcement implications that follow. My goal is to provide a useful framework in which the issues surrounding the behavior of firms in

designed to maintain its monopoly in personal computer operating systems, and to extend that power to Internet browsing software.

2 In writing this article, $I$ have relied in part on remarks made by former Deputy Assistant Attorney General Carl Shapiro in his March 27, 1996 address to the 44th Annual Antitrust Spring Meeting of the American Bar Association. More recently, Assistant Attorney General Joel Klein has reflected on the role of antitrust enforcement in a high-technology world (The Importance of Antitrust Enforcement in the New Economy, Address Before the New York State Bar Association Antitrust Law Section Program (January 29, 1988)). 
computer software and other dynamic high-technology network industries can be evaluated.

\section{Economic principles and their antitrust implications}

\section{A. Monopoly power in dynamic network industries}

Because there has been so much discussion of network industries, it is worth taking a moment to clarify this important concept. The word "network" applies to the underlying economics of an industry, not to the hardware or software associated with the product. Network industries are created by network effects, whereby each individual's demand for a product is positively related to the usage of other individuals. Many markets are characterized to one degree or another by this phenomenon. Network effects might arise in the context of computer software, for example, because users prefer a word processing program that is the program of choice of other users. In some cases, network effects are mediated through complementary goods as well. Again in the software context, developers are likely to write to an operating system that is favored by many people, while conversely, the greater the number of popular software applications, the more successful an operating system is likely to be.

While interest in network industries has grown recently because of increasing economic activity involving dynamic industries where there has been substantial innovation and rapid technological change (such as computers and communications), more traditional industries where fads or bandwagon effects may arise (such as designer jeans) are also characterized to some degree by a form of the same phenomenon. It is useful to distinguish between two basic types of networks in dynamic industries: communications networks (where consumers value a large network of users with whom to communicate, such as compatible telephone systems and compatible fax machines); and "virtual" networks or "hardware-software" networks, where there is not necessarily any communication between users on the network. ${ }^{3}$ Not all networks

3 For a thorough discussion of the economic characteristics of computer software markets and the antitrust implications that follow, see 
require communication. Suppose, for example, that many software users prefer a particular operating system. This could encourage software developers to produce more applications for this platform, generate greater competition in these complementary markets, and support the growth of a widespread technical support community specific to these products. The network effect arises in this case because the increased software development will enhance the value of the particular operating system and therefore increase its demand. To the extent that products and services complementary to a particular operating system are not transferable at low cost to other operating systems, economies of scale in producing these complements will tend to create (virtual) network effects in operating systems, even without communication among users of the network.

In industries in which network effects are significant, there is an increased likelihood that a single firm may come to dominate the market and to persist in that dominance. However, markets with a single dominant firm need not be markets in which there is a single technological standard that is met by all firms. Nevertheless, it is often the case that in industries with network effects users will naturally tend to gravitate toward using compatible products that are compatible with products owned by the greatest number of other users. For this reason, a firm that initially has a larger community of users than does its rivals may become dominant if the products of rivals are not compatible with its own. Such a firm may, in fact, have an incentive to adopt competitive strategies that support a single standard by preventing the products of rivals from achieving compatibility. ${ }^{4}$ Where it chooses to do so, or if the costs of guaranteeing compatibility across networks are high, the products of rivals can become relatively less desirable to users even if they appear to be of comparable (or pos-

Michael L. Katz \& Carl Shapiro, Antitrust in Software Markets, Paper Prepared for the Progress and Freedom Foundation Conference, Competition and the Microsoft Monopoly (Feb. 5, 1998).

4 Network effects apply to a wide array of industries with potentially varying legal consequences. See Mark A. Lemley \& David McGowan, Legal Implications of Network Economic Effects, CAL. L. REV. (forthcoming). 
sibly even higher) quality from a purely "technical" standpoint. When the dominant firm's product becomes the standard for the industry, firms that are developing alternative standards may find it difficult to compete effectively. 5

Industry standards take many forms, and the existence of an industry standard is neither a necessary nor a sufficient condition for the marketplace to be dominated by a single firm. In some instances, as with the DOS/Windows PC operating system or the Intel Pentium chip, standards are proprietary and could be strategically manipulated by their owner to make entry more difficult and competition less effective. In other instances, industry standards are nonproprietary and there exists considerable competition among firms within the same network. Examples include competition among manufacturers of fax machines (the products of which have achieved compatibility with one another by adhering to a common standard for encoding information), competition among television manufacturers (who design their products to be able to utilize the same format), and competition among manufacturers of VCR machines and VCR tapes. Moreover, even where standards are proprietary, there can be considerable competition to become the standard, and there can be strong competition among coexisting networks ("multiple standards") where network effects are sufficiently limited or offsetting factors sufficiently strong to permit multiple networks to survive in the marketplace. ${ }^{6}$

With dynamic network industries there are few generalizations that apply across the board. One might be drawn to the conclusion that network effects necessarily generate a dominant standard, but this is not necessarily the case. If competing products associated with different standards offer significantly different attributes, dif-

5 For a more thorough analysis of how the degree of compatibility affects the nature of competition in network markets, see Joseph Farrell \& Michael L. Katz, The Effects of Antitrust and Intellectual Property Law on Compatibility and Innovation, in this issue of The Antitrust Bulletin.

6 Mark A. Lemley, Antitrust and the Internet Standardization Problem, 28 CONN. L. REv. 101 (1996), suggests that by creating a barrier to entry, standardization can make recoupment and therefore predatory anticompetitive behavior more likely. 
fering standards (and products) that appeal to different tastes or groups may coexist. One example is the market for high-speed, high-quality computer games, in which Sega, Nintendo, and Sony (with its Playstation player) all compete and there is no dominant standard. Interestingly, leadership in this market has changed over time as products have gone through their life cycles, with Atari the initial leader, Nintendo a successful challenger to Atari, and Sega, a more recent rival of Nintendo. Here, while it may or may not be the case that individual platforms provide each of these firms with some degree of market power over "locked-in" consumers, competition among platforms for new users is intense and it is not obvious that any single firm will become dominant in the marketplace. Another example is mainframe computing, in which IBM and DEC each have different operating system interface standards, have competed with each other by offering products with features and capabilities of interest to customers, and have attempted to induce independent software and hardware vendors to plug into those standards to make their products more attractive.

It is important to understand that there are both benefits and costs associated with dominance by a single firm setting a single standard. In markets with standards created by network effects, users gain by adapting compatible technologies. Economies of scale (lower average costs of production with increasing scale) are often present (but need not be). ${ }^{7}$ Typically, standards go hand in hand with economies of scale when there are scale economies in the production of complementary products. For example, there are increasing returns in programming applications for a particular operating system, since many applications on which demand for a particular operating system is ultimately based are more costly to write for two operating system standards than for one. However, the fact that network effects will in some circumstances make it efficient to have a single network does not in and of itself imply that it is most efficient for the winning standard to be owned and

7 The term "increasing returns" has been popularized by BRIAN ARthur (INCREAsing Returns and Path Dependence In the Economy (1994)) as a description of the substantial change in output as technology improves. 
controlled by a single firm. In fact, in many instances standards are developed and controlled by a formal standards body (as, for example, with the ISO MPEG-2 compression standard, the context for a patent-pool Business Review Letter the U.S. Department of Justice issued last year) or by a collection of industry participants. I should be clear that I am not asserting here that standards should necessarily be controlled by industry committees or by a regulatory authority. There are, however, important and complex issues, both economic and legal, surrounding the appropriate scope of intellectual property protection, and related questions dealing with the costs and benefits of permitting important standards to be controlled completely by a single firm. ${ }^{8}$

Network industries often (but not necessarily) involving tipping, a point at which the joint existence of two incompatible products may be unstable, with the possible consequence that a single product and standard will dominate. Tipping can occur very rapidly (and long before disinterested outside observers realize it has happened). If firms are competing on the basis of innovation and if network effects make it likely that the better product will win the battle to dominate a market, then the competitive process can be beneficial. To the extent that tipping maximizes the size of the network, it does create consumer benefits. However, tipping also creates monopoly power that can be used for anticompetitive ends. ${ }^{9}$ With tipping, exclusionary practices that deny access to established standards can be particularly effective. A partial explanation is that with network industries psychology (the perceptions of users about the extent that the market will tip) often becomes intertwined with economics. It is possible, for example, that tipping can arise with no change in product design or product price, simply because of a change in the expectations of a substantial number of users about the likely eventual size of the net-

8 Joseph Farrell has argued that copyright protection should be narrow when it involves interfaces. See Standardization and Intellectual Property, 30 JuRImetrics J. 35 (1989).

9 Network effects are not necessary for tipping; tipping can occur in any market with substantial scale-related economies, whether on the supply side or the demand side. 
work. As a result, a firm currently competing or planning to compete in a tipping market has a substantial incentive to affect expectations by increasing the perception that its product is likely to become the network standard. ${ }^{10}$ It is the crucial significance of expectations that explains why dominant firms in network industries may have an incentive to engage in the tactic of vaporwarethe preemptive, intentional announcement of a product releasein an effort to prevent rival products and potential alternative standards from developing sufficient momentum to unseat the incumbent or to discourage a firm from entering a market in the first place. ${ }^{11}$

The possibility of a market's tipping can also affect the pricing strategies of firms. In dynamic high-technology markets, it is often efficient for firms to compete jointly for today's and tomorrow's markets. As a result, a number of firms may have an incentive to utilize "penetration pricing" to win the battle to control a market. Such a penetration strategy may involve pricing below short-run marginal cost, so that a firm can increase its probability of winning the battle to be the market standard. However, a firm that has substantial market power, and therefore a leg up in the battle for dominance, may find a low-introductory-pricing strategy to be an effective predatory strategy. Distinguishing between penetration and predatory pricing is therefore conceptually difficult. A predatory strategy is a strategy that would not be profitable without the recoupment of foregone profits because a competitor has left the market. In this context, a predatory strategy can neither be characterized solely by whether a product price at a particular point in time is low, zero, or even negative, nor by whether a firm currently dominates a market. Rather a predatory pricing policy is likely to be one in which a firm's current pricing cannot be profitably sustained even if the firm succeeds in achieving dominance and therefore obtains the benefit of economies of

10 The discussion in Farrell \& Katz, supra note 5, of the case in which expectations stubbornly favor one firm is particularly relevant here.

11 Truthful preannouncements can, of course, be procompetitive to the extent that they provide valuable and timely advance information to producers of complements and to final consumers. 
scale and access to revenue streams from complementary markets-revenues that could not be accessed more effectively by other means. ${ }^{12}$ It may also be useful to treat pricing by a company that is trying to enter a new market by launching a new product with less suspicion than pricing by a firm with an already-established product.

Predatory pricing is not the only possible strategy that a firm may use in trying anticompetitively to eliminate current competition or deter future competition. Other predatory strategies can be used effectively by a dominant firm to thwart efficient entry and/or to deter efficient innovation, and these may be of particular concern in dynamic high-technology industries. Assume, for example, that a firm is considering the possibility of innovating in one or more product markets that are complementary to the product controlled by a dominant firm. ${ }^{13}$ The competitor is unlikely to make such an effort unless it expects to earn (at a minimum) a normal economic rate of return. As a result, the dominant firm can for predatory reasons make the innovations of competitors unprofitable-in a variety of ways. First, it can calculate the maximum price consumers would be willing to pay for a "system" comprised of its product and that of the newly developed complement, and charge consumers enough for its monopolized component that the innovator is unable to charge sufficiently for its complement to enable the innovator to earn a reasonable return. Second, the dominant firm can make it clear that its product is or will be designed so as to be incompatible with the innovator's product. Third, it can discourage the innovator by offering or making plans to offer a close substitute for the competitor's innovative product at a "predatory" price. ${ }^{14}$ Finally, by threatening to integrate its

12 It is appropriate conceptually to include as complementary revenue streams only those revenues that would have been received absent any other illegal acts by the dominant firm.

13 In many cases the dominant firm will find it profitable for nonpredatory reasons to want to extend its successful performance into the complementary market; extension in itself is not a problem.

14 This could represent traditional predatory pricing if the monopolist would find it profitable to engage in this investment and pricing strategy only on condition that the entrant be driven out of the market. 
dominant product together with its (perhaps somewhat late-tomarket) version of the innovator's product, the monopolist may be able uniquely to avail itself of ubiquity in distribution-making success of the innovator's product unlikely. ${ }^{15}$

Why should the dominant firm discourage the competitor's innovative efforts? One answer is horizontal-the firm may wish to discourage innovation that might create a product or products that threaten the firm's current market position. Another answer, however, is vertical-the dominant firm might wish to discourage innovation in a complementary market. Such innovation by the firm could create substantial benefits and be (on balance) in the social interest. However, it is also possible that by deterring innovation in the complementary market, the dominant firm will have created a stronger barrier to entry into the market for its dominant product; in the end this stronger barrier will allow the dominant firm to recoup any foregone profits. Two-level entry into the dominant firm's product market and the complementary product market simultaneously can be substantially more difficult than one-stage entry. (In effect, a firm that wants to compete in the dominant firm's market must by necessity enter into the complementary market as well. ${ }^{16}$ )

There are a number of complexities here that must be sorted out. First, a dominant firm will have a legitimate interest in innovating and entering into complementary product markets, since (among other things) this will enhance the value of the dominant firm's product; one must therefore be able to distinguish predatory from nonpredatory strategies. Second, if integration by a dominant firm creates some efficiencies, innovation in complementary markets by others may be deterred not so much because the

15 I am presuming that such an action would otherwise (absent the possibility of recoupment) not be profitable.

16 The idea that vertical mergers may impede entry because of the requirement for entry at two levels has received extensive discussion in the economic literature. See, for example, William S. Comanor, Vertical Mergers, Market Powers, and the Antitrust Laws, 57 AM. ECoN. REv., PAPERS \& PROC. 254, 259-62 (1967). The concept was endorsed by the 1984 Merger Guidelines, $\S 4.212$, reprinted at 4 TRADE REG. REP. (CCH) ก 13,103 . 
incumbent is "predating," as by the competitive threat created by the efficiencies itself.

ANTITRUST IMPLICATIONS With network industries, especially those in which tipping is a real possibility, allegations of anticompetitive behavior need to be treated quickly and seriously. Once the market has tipped it may be difficult or even undesirable to undo any anticompetitive effects that have arisen (e.g., to switch locked-in users to another standard or to impose compatibility requirements that are otherwise not in effect). It is appropriate, therefore, to evaluate a firm's pricing strategy along the lines suggested previously to see whether a low, zero, or even negative price is symptomatic of a penetration pricing strategy that could have been chosen by other (similarly situated) competitors in the industry, or whether the pricing strategy is predatory. Such a strategy would presumably not have been chosen but for the dominant firm's market power, and would have the goal of eliminating competition with the prospect of obtaining, maintaining, or increasing monopoly power and ultimately recouping any short-run profits that were foregone. In dynamic high-technology network industries predation that discourages innovation can be an effective anticompetitive strategic tool. However, in the process of doing its own innovation, a dominant firm can substantially deter entry into the market for its dominant product simply because it is successful in competing on the merits. The challenge for antitrust law is to distinguish legitimate procompetitive innovation strategies that harm competitors simply because they are successful from those that are motivated for predatory reasons.

It is tempting to conclude that competition on the merits among firms in high-technology network industries will insure that if a dominant standard arises, that standard will necessarily be the most desirable from a social point of view. While consumer choice will give a competitive advantage to a better technology and a better product, the best products will not necessarily win the battle to become the network standard. Further, since groups of consumers may differ in their valuation of the attributes of a particular standard, we cannot be certain that the majority of users will be pleased with the chosen standard. In the computer soft- 
ware business, for example, users may differ in their valuation of operating systems. Some operating systems may be particularly easy to use for the average consumer, while others may be particularly suitable for applications programmers to write to. Having said this, it would nevertheless be inappropriate as a rule to second-guess the market's choice of a standard, if that choice resulted from competition on the merits.

This line of thinking might suggest the possible ex post application of antitrust enforcement; one would wait until a standards battle had been fought and then, with hindsight, evaluate the winning standard. If a particular standard were not deemed to be the "best," corrective intervention would be given serious consideration. There are at least three reasons to be hesitant to utilize such a policy prescription. First, it is not easy to evaluate what is best, even ex post, since preferences of consumers and users may vary. Second, what may be clear with hindsight, may not have been clear when the relevant economic choices were made. For legal rules to be meaningful, they must be sensible ex ante; they cannot simply be applied ex post with hindsight. Third, even if there is a clear "winner," it may be very costly to remedy the situation. Aside from the obvious cost of imposing a new standard on the market, ex post intervention could adversely affect ex ante incentives. Specially, firms that are actively competing on the merits to become dominant may be overly cautious in pursuing beneficial innovation and pricing strategies for fear of later "corrective intervention." (If you know that success will be punished, you are less likely to innovate.)

If dominance can be socially desirable, and a dominant position earned by appropriate procompetitive (and sometimes innovative) behavior does not merit antitrust enforcement, what is the significance of dominance? One important answer is that dominance in one market can affect (positively) the likelihood of success in markets for complementary products (which will in turn increase the incentive to compete to win the first market). There are several reasons for this, some of which are clearly procompetitive and some which may be anticompetitive. In many instances a firm that has achieved dominance in one market for productive 
reasons (and not luck or predatory actions) is likely to be able to exploit significant economies of scope (in research, design, marketing, support, etc.) that make it the low-cost producer and supplier of complementary products. Further, consumers may prefer to purchase their complements from a firm that has a monopoly in a related product. The ability of consumers to evaluate product quality ex ante is typically imperfect, but consumers often do perceive that a monopolist may have a particularly strong economic interest in providing high quality complements (so as to enhance the reputation and demand for their monopoly product). Thus, while entry by a monopolist into a complementary market need not always be competitively benign, the fact that we see so many firms in the economy-even those with little or no market power-operating in related markets, suggests that there may be an efficiency explanation for this phenomenon that should be taken into account even when evaluating the behavior of firms with substantial market power.

The antitrust analysis of firm behavior becomes particularly difficult when it comes to evaluating the particular price and nonprice competitive strategies that firms use to increase the likelihood that they will become dominant in one or more related markets. As I explained previously, these policies may be pursued because they provide advantages to the firm that also benefit consumers, they may be pursued because they allow a firm to increase its market power or to exploit its existing market power, or a combination of the two. Where would-be rivals are not in a position to match or otherwise counter the strategies employed by a dominant incumbent, efficient entry may be thwarted. If it is predatory, it is likely to be part of a strategy not available to other competitors that is directed toward the elimination of competitors with the hope that short-term profits foregone can be recouped at a later date. Similarly, attempts to foreclose a rival's channels of distribution or other business arrangements that exclude competitors can be anticompetitive.

Two broad principles seem particularly significant here. First, as suggested earlier, if it is appropriate for antitrust to intervene in tipping markets, it is essential that intervention take place at an 
early stage. Once the point is passed at which expectations in the marketplace have been significantly affected, it will be more difficult to intervene successfully. One implication of this is that it can be easier and more effective from a policy perspective to open existing interfaces, for example, by requiring that operating system APIs (application programming interfaces) be made publicly available at an appropriately early date than it will be to change an existing standard. ${ }^{17}$ Second, intervention can be inefficient, particularly in the long run, if it penalizes dominance that is the result of innovative efforts and not the result of fortuitous events or anticompetitive practices. Such a policy will "have the effect of taxing technological improvements," 18 and taxing something generally means you get less of it. (To be sure, ill-considered intervention can also be inefficient even in the short run, to the extent that it prevents even a dominant firm from responding aggressively, but fairly, to competition.)

One final, important reminder. These antitrust principles apply to dominant firms--defined to characterize firms that have substantial market power. Business conduct by dominant firms that should be given careful scrutiny and that may be anticompetitive, is likely to be harmless if carried out by firms with little or no market power. Moreover, the fact that practices are put into effect by firms with little market power suggests that there are real efficiencies associated with those practices. When exercised by firms with substantial market power, however, the same conduct could on balance be anticompetitive because it distorts competition more than it aids it.

\section{B. Innovation and market competition}

In evaluating markets with relatively homogeneous products and a fixed or slowly evolving technological base, the Antitrust

17 For a useful discussion of software interfaces see Peter S. Menell, An Epitaph for Traditional Copyright Protection of Network Features of Computer Software, in this issue of The Antitrust Bulletin.

18 Kenneth Arrow, Declaration, in United States of America v. Microsoft Corporation, Motion to Enter Final Judgment, Civil Action No. 94-1564 (SS), January 17, 1995. 
Division often focuses on the price effects of potentially anticompetitive behavior. In dynamic network industries, however, technological change and innovation as well as price receive substantial attention. Innovation affects not so much the prices that consumers pay for given products, but more importantly innovation affects the quality of products in the marketplace and especially whether dramatically new and better products will come into existence. It is the force of innovation that can lead to higher quality products being offered at lower prices to consumers in the future. An understanding of the particulars of competition in dynamic network industries is a vital part of a sound antitrust policy. ${ }^{19}$

In dominant network industries the market is often a moving target, evolving as technology changes in response to innovation. It is important, therefore, to focus not only on static competition within the market as it is currently constituted, but also on dynamic competition for the market of the future, i.e., competition to control the next market standard (if there is one). For example, IBM historically dominated the mainframe operating system market; at the time of the emergence of PCs as popular products, the role of IBM as a competitor in the newly developing PC operating system market had significant implications for innovation in operating systems for this product. A more current example may be Sun's cross-platform Java initiative, which presents a potential competitive threat to the Windows platform.

ANTITRUST IMPLICATIONS We have seen that with competition in dynamic network industries the forces that drive the winner to be the most efficient are not always as reliable as they would be in nonnetwork markets. Further, it is sometimes socially costly to move from a less to a more efficient standard (i.e., there may be

19 The importance of innovation as a driving force in economic growth has been a subject of frequent commentary. Technology and innovation markets were recognized explicitly in the 1995 DOJ-FTC's Antitrust Guidelines for the Licensing of Intellectual Property, The importance of new and improved products is discussed in FEDERAL TRADE Commission StafF, Anticipating tHe 21st Century: Competition Policy aNd the New High-Tech, Global Marketplace 11-24 (May 1996). 
lock-in effects making it difficult to change a standard, and the social cost of changing the standard may exceed the benefit of changing). ${ }^{20}$ Thus, while innovations that benefit consumers are clearly to be encouraged, evaluating whether a particular innovation is desirable, or ascertaining the rate at which particular innovations are made, is a more difficult exercise. The implication once again is that early intervention that encourages competition on the merits is to be preferred to late intervention after the standard has been determined.

Dynamic network industries present substantial opportunities for firms to manipulate standards for anticompetitive advantage.21 However, in dynamic network markets, control over a standard today does not necessarily create any long-term advantage, since it may not be easy to leverage or otherwise successfully migrate a user from one standard to another. Dynamic network markets are often characterized by path dependence, i.e., the path of innovation is often determined by historical events that may or may not be tied to efficient procompetitive behavior. ${ }^{22}$ As a result, the timing of antitrust intervention can be significant. ${ }^{23}$

20 See Brian Arthur, Competing Technologies, Increasing Returns, and Lock-in by Historical Events, 99 EcoN. J. 116 (March 1989). Arthur suggests that lock in can result when the following are important: (a) fixed costs; (b) learning effects; (c) coordination effects; and (d) adaptive expectations.

21 In static markets, there often is less controversy over standards because the technology is relatively fixed and the standdards are settled. In the bolting industry, for example, there are standards for the width of the threads, their depth, their angle of inclination, etc. These standards are settled, even though the standards are different in the U.K. and the U.S. A similar story applies to electric outlets for plugs and to light bulb sockets. (This is not to say that incumbents in static markets do not have an incentive to abuse an existing standards committee to keep out rival technologies.)

22 See Douglas C. North, Institutions, Institutional Change and ECONOMIC PERFormance 112 (1990), for an elaboration.

23 Michael Katz \& Carl Shapiro, Systems Competition and Network Effects, 8 J. ECON. PERSPECTIVes 93 (1994), suggest that path dependency and timing are likely to be less significant in a strategic setting because a dominant firm can and will act to tip the market in its preferred direction. 
Intervention need not be required, however. Dynamic changes can, even absent intervention, cause a firm to lose dominance. For example, IBM lost much of its former dominance in computers, thanks to dynamic developments such as the major, exogenous technological advances in microchip technology that enabled smaller and much cheaper computing platforms (first minicomputers, and shortly thereafter the PC), to do much the same work that mainframes had long done (and at only a fraction of the cost).

\section{Installed base}

As stated earlier, dominance earned as the result of a valid competitive process, in itself, should not be of concern to the antitrust authorities. However, having substantial market power can provide an opportunity for a firm to pursue anticompetitive strategies that raise rivals' costs and effectively foreclose opportunities. With control over a large installed base, a dominant firm clearly has an incentive to innovate to grow the demand for its products among new users as well as among its existing, lockedin installed base. Further, the dominant firm will find it advantageous to bring to market a product that is particularly attractive to its current installed base. Catering to the installed base in this manner can be efficiency enhancing. However, an innovation strategy that is likely to detract from the ability of others to compete in that line of business, perhaps by making it difficult to produce a compatible product, is troubling. Also of concern is the possibility that the dominant firm will innovate more slowly and incrementally than if it had no market power.

The debate about the effects of dominance on innovation is one that is not likely to be fully resolved in the near future. Because a dominant firm has a near monopoly, it (like any competitor) has an incentive to innovate so as to maximize its chance of controlling that moving target (the market). However, the dominant firm also will take into account the effect of its innovative effort on the profitability of its existing franchise. As a result, the quantity and quality of innovation in an industry could be adversely affected if the industry has a single dominant firm that goes beyond competition on the merits to utilize business prac- 
tices that protect it from effective competition from other firms. While that firm does have an incentive to innovate, the degree of innovation is likely to be affected by the firm's installed base. Further, there may be less incentive on the part of the dominant firm's rivals to expend the R\&D funds necessary to win the dynamic competition for the market, since the likelihood of a successful effort will be small. ${ }^{24}$ An ambiguity remains, of course, since the rewards from success may be greater, leaving the net effect indeterminate.

With consumer preferences for uniformity in products and compatibility in complementary products, dominant firms operating with a single standard are likely to develop in dynamic network industries. It is important to understand, however, that not all network industries will involve single standards, and moreover, multiple standards may, under some circumstances, be more efficient. In such situations, efforts by dominant firms with substantial installed bases to encourage uniformity may reflect narrow self-interest rather than consumer welfare.

Fragmentation (multiple standards) does have its costs; in some cases it can cause consumer confusion; in other cases, product designers may have to develop their products for multiple platforms rather than only one. However, fragmentation can be socially beneficial. For one thing, consumers with different tastes can be accommodated. ${ }^{25}$ For another, fragmentation can encourage more and higher quality innovations, particularly those that are directed toward winning the battle for new markets. While firms can innovate to try to become the next standard, such innovation is more likely to be profitable if there are more "success-

24 Kenneth Arrow demonstrates that monopolists may innovate less than firms in very competitive markets. See Economic Welfare and the Allocation of Resources for Invention, in NATIONAL BUREAU OF ECONOMIC Research, The Rate and Direction of INVENTTVE ACTIVITY: Economic and Social Factors 609-25 (1962). See also Frederick M. SCHERER \& DaVid Ross, Industrial Market Structure and Economic Performance (1990), for some cross-sectional tests of this proposition.

25 Note that if it is not costly to insure compatibility, and if firms have an incentive to work toward it, in some instances a single network can accommodate consumers with different tastes. 
ful" firms in similar markets to begin with, e.g., if there are multiple operating systems with multiple installed bases that can be migrated by their owners to the future.

A recent example of the potential benefits of fragmentation is illustrated by the January 22, 1998 decision of Netscape to make the source code for its next-generation browser, Communicator 5.0, available for free on the Internet. Public access to the source code will allow programmers to customize Communicator for their own particular preferences. ${ }^{26}$ The resulting "fragmentation" has the potential to build support for Netscape's product, particularly if the modifications of the program remain compatible with each other. Whether the benefits of customization to the varied users of browser software will be sufficiently enticing to a large number of users to improve Netscape's competitive position, or whether fragmentation and potential incompatibilities will create more problems than solutions, remains to be seen.

ANTITRUST IMPLICATIONS In dynamic network industries, with substantial innovation and declining quality-adjusted product prices, there remains an important role for antitrust enforcement. The relevant question is not whether there is innovation, but whether the quantity and quality of innovation would be significantly improved were the dominant firm to make its business decisions on the basis of real economic efficiencies, and not on the expectation of benefiting from the firm's market power associated with its substantial installed base of users, and with its attempt to acquire or maintain substantial market power.

\section{Leveraging}

Leveraging occurs when a firm uses its advantage from operating in one market to gain an advantage in selling into one or more other, generally related markets. Leveraging by dominant firms may take place for a variety of reasons that can be procompetitive or anticompetitive, depending on the circumstances. With respect to the former, leveraging can be seen as a form of vertical

${ }^{26}$ Carl Shapiro \& Hal R. Varian, A Judo Blow Against Microsoft, Wall ST. J., Feb. 2, 1998, at A-22. 
integration in which the firm may improve its distribution system, economize on information, and/or improve the quality of its profits. Further, if the dominant firm can produce a related product better (perhaps in the process maintaining an open interface standard), or if it enters a related product market because there is insufficient competition in that area, there is unlikely to be an antitrust problem.

Leveraging can, however, be anticompetitive if it serves as a mechanism by which a dominant firm is able to raise its rivals' economic costs of competing in the marketplace. Whether such leveraging is in fact anticompetitive is a complex issue, however, since there are potential efficiencies that may be at issue. For example, in its effort to be adopted as the next generation standard (or trying to move consumers from one equilibrium to another), the owner of one element of a system may want to enter complementary markets by engaging in alliances as part of a strategy of attracting users to its network. ${ }^{27}$ Such an effort could on balance be anticompetitive, and could in fact be motivated by an effort to increase its competitors' costs of developing an effective competing product, and as a result, foreclose competition. However, there may be real economic advantages (e.g., compatibility, efficiencies in distribution) that flow from the offering of two products that work especially well together.

It is important that competition in markets for complementary products be based on the merits and not be diminished by the strategic behavior of a firm with a dominant position in a market. One particularly troubling aspect of leveraging is the possibility that innovation incentives of competitors will be decreased. Such a blunting of incentives can occur if the leveraging practice is undertaken not primarily as part of a vigorous competitive strategy, but in part to decrease the likelihood of competitor entry, so that the dominant firm will continue to be victorious in the com-

27 Because users may be hesitant to commit to any given system unless they believe it will be adopted by many others, the "network owner" may engage in a variety of strategies (including expanding into complementary products and offering a wide variety of complementary products at reasonably attractive prices) as a way to insure potential buyers against the possibility of a small, low-value network. 
petition for the next market. The fact that this likelihood of success can reduce the incentives of other competitors to innovate is particularly significant because markets in which there is rapid technological progress are often markets in which switching costs are high - users find it costly to switch to a new technology that is not fully compatible with the older technology. The result is an increase in entry barriers.

Leveraging can be accomplished by a variety of practices (e.g., tying, bundling, exclusive dealing, low pricing), each of which may have anticompetitive or procompetitive aspects, or a combination of the two. Inevitably, an evaluation of each particular practice in context will be necessary before a clear conclusion can be reached. With commercial tying, a firm conditions the purchase (or license) of one product-the tied product-on the purchase (or license) of another product-the tying product. There are a number of procompetitive reasons that a firm might choose a tying arrangement, including cost savings (it could be less expense to offer a package) and quality control (it could be easier to sort out the source of quality problems with a tied sale than if the products are sold separately). However, tying can be anticompetitive and it can be an effective leveraging practice.

Traditionally, tying has been viewed as a device that allows a firm to price discriminate. ${ }^{28}$ However, tying can also be a practice that forecloses competition in network markets. Suppose, for example, that a dominant firm has a product with a current technology that is supported legally by its intellectual property rights. Suppose further that the firm offers to license its technology only to those firms that agree to also license that firm's complementary

28 Suppose, for example, that a dominant firm is not able to fully monitor the sales of a particular product (perhaps because of piracy). A tying arrangement, which allows the firm to "meter" the sales of a complementary product, could provide a mechanism by which the firm can increase its monopoly rents. More generally, tying can be an effective device for raising rivals' costs and thereby strategically foreclosing competition. See, for example, Frank Mathewson \& Ralph Winter, Tying as a Response to Demand Uncertainty, 28 RAND J. EcoN. 566 (1997). See also Michael Whinston, Tying, Foreclosure, and Exclusion, 28 AM. EcoN. REV. 837 (1990). 
product, and suppose that the complementary product builds on the firm's next generation technology. Such a tying arrangement could allow the dominant firm to create a new installed base of users of its next generation technology in a manner that would effectively foreclose the opportunities of competing firms to offer their products in the battle for the next generation technology. ${ }^{29}$

Another potential leveraging device is the practice of bundling. Pure bundling occurs (in this context) when the dominant firm sells its monopoly product together with its version of a complementary product at a single price (that is less than the sum of the products sold individually). In effect, the dominant firm tells its customers: You don't get my monopoly product at a discount unless you take my version of this separate product as well. (Contrast this with tying, where the tied product can be purchased separately.) Dominant firms may bundle products to their anticompetitive advantage when unbundling would be socially desirable. ${ }^{30}$ Interestingly, firms with market power may also find it advantageous to offer their products as a mixed bundle (i.e., separately offering a bundled product and two unbundled products). Office productivity suites are currently sold in such a mixed bundling format, with each potential purchaser given the option of purchasing the entire suite or the individual software applications that comprise the suite. While mixed bundling can also be an effective exclusionary device, an evaluation of the effect of bundling on competition will, of necessity, be dependent on the market at issue and the particulars of the bundling arrangement. ${ }^{31}$

29 See, for example, Joseph Farrell \& Garth Saloner, Installed Base and Compatibility: Innovation, Product Preannouncements, and Predation, 76 Am. ECON. Rev. 940 (1986).

30 For an analysis of the implications of Microsoft's bundling of its TCP/IP protocol stack into Windows 95, see Willow Sheremata, Barriers to Innovation: Monopoly, Network Externalities, and the Speed of Innovation, 42 ANTITRUST BULl. 937 (1997).

Note, however, that pure bundling may be procompetitive. (For a general discussion of pure and mixed bundling, see, for example, $\mathrm{R}$. PindyCK \& D. RubINFELD, Microeconomics $\S 11.5$ (4th ed. 1998)).

31 With mixed bundling, forcing a buyer to take the tied product at a discounted price can be seen as a form of tying. 
ANTITRUST IMPLICATIONS Whether through tying, bundling, or a host of other practices, the leveraging of market power from the sale of one product to the sale of a related, complementary product is worthy of antitrust scrutiny. Inevitably an evaluation of the anticompetitive effects of leveraging behavior will be fact-dependent. Leveraging practices can provide consumer benefits that flow from the fact that a single firm is jointly producing and selling two products. However, leveraging may also be anticompetitive if it provides a means by which the firm is able to monopolize or attempt to monopolize other complementary product markets. Where it threatens to do so, an important and disturbing effect may be to discourage innovative behavior by actual or potential competitors.

III. Conclusion: some principles for antitrust enforcement in dynamic network industries

The preceding discussion should not be seen as suggesting that there is a need for an entirely new application of current antitrust law, or for that matter for new laws. To the contrary, I believe that the current antitrust framework is adequate for the task ahead. It is important, however, that we think carefully about the particular application of antitrust principles in the complex dynamic world of network industries. As these principles are applied to dynamic networks generally and to computer software in particular, the following broad tenets should not be forgotten:

1. The antitrust laws exist to protect competition.

2. The antitrust laws are not designed to penalize successful companies when their success is based on behavior that creates efficiencies and benefits consumers.

3. The antitrust laws are directed toward restricting specific practices that are likely to be anticompetitive because such practices are not. in the long-run interests of consumers.

4. What's good for a successful company need not always be what's good for the economy. 
5. Successful firms are not permitted under the antitrust laws to engage in predatory or exclusionary conduct, the effect of which is to insulate themselves from the forces of competition.

6. Neither the fact that the rate of advancement of technology is rapid, nor the fact that the price of many products is falling, should be a barrier to the appropriate "surgical" application of antitrust principles to restrict anticompetitive behavior.

7. Antitrust interventions will, to the extent possible, be undertaken with a minimal degree of disruption and cost to the firms involved, and to the competitive process.

I conclude that the application of antitrust enforcement principles to dynamic network industries is intellectually demanding and yet vitally significant. I have suggested that a variety of competitive practices adopted by firms without market power in network industries are likely to be efficiency based, whereas practices of a dominant firm may have anticompetitive implications (as well as efficiencies) for competition among market competitors and for competition in complementary markets. Distinguishing those practices that are on balance anticompetitive from those that involve competition on the merits will continue to be a vitally important, yet difficult exercise. 